\title{
Biological Screenings of Two Araceous Plants Growing in Bangladesh
}

\author{
Tanjina Hoque ${ }^{1}$, Md. Al Amin Sikder ${ }^{1}$, Mohammad A. Kaisar ${ }^{2}$, Abu Asad \\ Chowdhury ${ }^{2}$ and Mohammad A. Rashid ${ }^{2}$
}

\author{
${ }^{1}$ Department of Pharmacy, State University of Bangladesh, Dhaka-1205, Bangladesh \\ ${ }^{2}$ Phytochemical Research Laboratory, Department of Pharmaceutical Chemistry, Faculty of Pharmacy, \\ University of Dhaka, Dhaka-1000, Bangladesh
}

\begin{abstract}
Two Bangladeshi medicinal plants from Araceae family, Alocasia indica and Steudnera virosa, have been investigated for their in vitro thrombolytic, membrane stabilizing antimicrobial activities and generalized toxicity. The total phenolic content was also determined and expressed in gallic acid equivalent. The membrane stabilizing activity was assessed by heat and hypotonic solution induced methods. The carbon tetrachloride soluble fraction (CTCSF) of A. indica and aqueous soluble fraction (AQSF) of S. virosa demonstrated strong membrane stabilizing activity. Different extractives of A. indica and S. virosa showed moderate thrombolytic activity. Among the two plants, the methanoic crude extract and its chloroform soluble partitionate of $S$. virosa revealed moderate inhibition of microbial growth. In brine shrimp lethality bioassay, the pet-ether and carbon tetrachloride soluble fractions of A. indica and the crude extract and its pet-ether soluble fraction of S. virosa were found to be as lethal as Vincristine sulphate after 24 hours observation on shrimp nauplii.
\end{abstract}

Key words: Alocasia indica, Steudnera virosa, thrombolytic, membrane stabilizing, total phenolics, antimicrobial.

\section{INTRODUCTION}

Alocasia indica (Linn.) and Steudnera virosa (Roxb.) belong to the family Araceae. It is a family of monocotyledonous flowering plants in which flowers born on a type of inflorescence called a spadix. Different parts of A. indica are used in the treatment of inflammation and in diseases of abdomen and spleen. The juice of the leaves of the plant is used as laxative, diuretic, astringent and traditionally used for the treatment of rheumatic arthritis. It has antifungal properties. This plant contains flavonoids, cynogenetic glycosides, ascorbic acid, gallic acid, mallic acid, oxalic acid, alocasin, amino acids, succinic acid and $\beta$-lectines. ${ }^{1}$

As a part of our continuing studies on medicinal plants of Bangladesh ${ }^{2,3}$, the organic soluble materials of methanol extract of the rhizomes of A. indica and

Correspondence to: Mohammad A. Rashid Tel.: 880-2-9661900, Extn.- 8130, 8131, 8137; Fax: 880-2-8615583; E-mail: rashidma@univdhaka.edu

Dhaka Univ. J. Pharm. Sci. 10(2): 131-135, 2011(December)
S. virosa were screened for antioxidant activity (in terms of total phenolic content), thrombolysis, membrane stabilization as well as antimicrobial and cytotoxic activities for the first time and we, herein, report the results of our preliminary studies.

\section{MATERIALS AND METHODS}

Plant materials. The rhizomes of A. indica and $S$. virosa were collected from Kishoregonj in March, 2011 and voucher specimens for these plants have been maintained in Bangladesh National Herbarium, Dhaka for future reference.

The rhizomes were sun dried for several days and then oven dried for 24 hours at considerably low temperature (below $40^{\circ} \mathrm{C}$ ) to facilitate grinding. The powdered materials of $A$. indica and $S$. virosa (each $500 \mathrm{gm}$ ) were seperately macerated in $2.0 \mathrm{~L}$ of methanol for 7 days and then filtered through a cotton plug followed by Whatman filter paper number 1 . The extracts were concentrated with a rotary evaporator at low temperature $\left(40-45^{\circ} \mathrm{C}\right)$ and reduced 
pressure. Each of the concentrated methanol extract (ME) was partitioned by the modified Kupchan method $^{4}$ and the resultant partitionates i.e., pet-ether (PESF), carbon tetrachloride (CTCSF), chloroform (CSF), and aqueous (AQSF) soluble fractions were used for the experiment.

Thrombolytic activity. The thrombolytic activity of all extracts was evaluated by the method developed by Daginawala (2006) ${ }^{5}$ and modified by Kawsar et al. (2011) ${ }^{6}$ using streptokinase (SK) as the standard.

Membrane stabilizing activity. The membrane stabilizing activity of the extractives was assessed by using hypotonic solution and heat-induced hemolysis of mice erythrocyte by the method developed by Shinde et al. (1999) ${ }^{7}$ and modified by Sikder et al. $(2011)^{8}$.

Total phenolics analysis. Total phenolic content of $A$. indica and S. virosa extractives was measured by employing the method ${ }^{9}$ involving Folin-Ciocalteu reagent as an oxidizing agent and gallic acid as the standard. To $0.5 \mathrm{ml}$ of extract solution $(2 \mathrm{mg} / \mathrm{ml})$ in water, $2.5 \mathrm{ml}$ of Folin-Ciocalteu reagent (diluted 10 times with water) and $2.0 \mathrm{ml}$ of sodium carbonate $(7.5 \% \mathrm{w} / \mathrm{v})$ solution were added. After 20 minutes of incubation at room temperature the absorbance was measured at $760 \mathrm{~nm}$ using a UV-visible spectrophotometer. Total phenolics were quantified by calibration curve obtained from measuring the known concentrations of gallic acid $(0-100 \mu \mathrm{g} / \mathrm{ml})$ and were expressed as mg of GAE (gallic acid equivalent) / gm of the dried extract.

Brine shrimp lethality bioassay. This technique was applied for the determination of general toxic properties of the DMSO solutions of plant extractives $^{10,11}$ against Artemia salina in a 1-day in vivo assay. Vincristine sulphate was used as positive control.

Antimicrobial activity. The antimicrobial screening, which is the first stage of antimicrobial drug discovery, was performed by the disc diffusion method $^{12}$ against thirteen bacteria and three fungi (Table-6) collected as pure cultures from the Institute of Nutrition and Food Science (INFS), University of
Dhaka, Bangladesh. Standard disc of Ciprofloxacin (30 $\mu \mathrm{g} /$ disc) and blank discs (impregnated with solvents followed by evaporation) were used as positive and negative control, respectively. The test material having antimicrobial activity inhibited the growth of the microorganisms and a clear, distinct zone of inhibition was visualized surrounding the discs. The antimicrobial activity of the test agents was determined by measuring the diameter of zone of inhibition expressed in $\mathrm{mm}^{13}$

\section{RESULTS AND DISCUSSION}

Two Bangladeshi medicinal plants Alocasia indica and Steudnera virosa belonging to the family Araceae have been investigated for their biological activities, with especial emphasis to the membrane stabilizing and thrombolytic activities.

As a part of discovery of cardio protective drugs from natural sources, the methanol extracts as well as the Kupchan fractions of A. indica and S. virosa were assessed for thrombolytic activity and the results are presented in Table 1. Streptokinase (SK) showed $66.77 \%$ lysis of clot whereas the negative control (water) exhibited a negligible percentage of lysis of clot by $3.80 \%$. The mean difference in percentage of clot lysis between positive and negative control was found to be statistically significant. In this study, different extractives of $A$. indica and S. virosa showed moderate clot lysis activity ranging from $45.61 \pm 1.200 \%$ to $20.51 \pm 0.818 \%$ and $49.75 \pm$ $3.090 \%$ to $32.35 \pm 0.999 \%$, respectively.

The membrane stabilizing activity of methanol extracts of $A$. indica and S. virosa was also determined. All the extractives significantly protected the lysis of human erythrocyte membrane induced by hypotonic solution and heat induced haemolysis, as compared to the standard acetyl salicylic acid. In hypotonic solution and heat induced conditions, the CTCSF of A. indica (Table 2) inhibted $53.81 \%$ and $17.37 \%$ haemolysis of RBCs, respectively as compared to $71.77 \%$ and $42.20 \%$ inhibition by acetyl salicylic acid, respectively $(0.10 \mathrm{mg} / \mathrm{ml})$ whereas AQSF of S. virosa (Table 3) demonstrated 54.74\% and $32.90 \%$ inhibition of hemolysis, respectively. 
The total Phenolic content of the methanol extract (ME) of rhizomes of $A$. indica and S. virosa and their different partitonates was determined and the results are summarized in Table 4.

In cytotoxicity screening, the lethality of the methanol extracts and various Kapchan fractions of both plants was evaluated against $A$. salina (Table 4). The PESF and CTCSF of $A$. indica and ME and PESF of $S$. virosa revealed potent cytotoxic activity, with $\mathrm{LC}_{50}$ values of $0.58 \pm 0.73,0.50 \pm 0.84$ and $0.47 \pm 0.91,0.49 \pm 0.79$, respectively.
The extracts were also subjected to screening of in vitro antibacterial activity against five gram positive and eight gram negative bacteria at 400 $\mu \mathrm{g} /$ disc by the standardized disc diffusion method. The results of antibacterial activity revealed moderate inhibitory activity against most of the tested pathogens by the ME, PESF and CSF of A. indica (Table 5) but no antimicrobial activity was observed for S. virosa (data not shown). The inhibitory activity of the extractives was compared with standard antibiotic, ciprofloxacin.

Table 1. Thrombolytic activity (in terms of \% of clot lysis) of $A$. indica and $S$. virosa.

\begin{tabular}{ccccc}
\hline \multicolumn{5}{c}{ A. indica } \\
\hline Fractions & W1 & W2 & W3 & \% of clot lysis \\
\hline ME & $0.821 \pm 0.005$ & $1.10 \pm 0.007$ & $0.092 \pm 0.006$ & $45.61 \pm 1.200$ \\
PESF & $0.805 \pm 0.004$ & $1.08 \pm 0.012$ & $1.03 \pm 0.008$ & $20.51 \pm 0.818$ \\
CTCSF & $0.739 \pm 0.008$ & $1.17 \pm 0.003$ & $1.01 \pm 0.002$ & $37.75 \pm 1.410$ \\
CSF & $0.875 \pm 0.003$ & $1.15 \pm 0.009$ & $1.07 \pm 0.006$ & $29.55 \pm 0.352$ \\
AQSF & $0.872 \pm 0.003$ & $1.13 \pm 0.010$ & $1.07 \pm 0.006$ & $21.80 \pm 0.906$ \\
\hline ME & $0.789 \pm 0.012$ & $1.07 \pm 0.018$ & $0.972 \pm 0.006$ & $32.39 \pm 3.830$ \\
PESF & $0.783 \pm 0.012$ & $1.18 \pm 0.045$ & $1.03 \pm 0.008$ & $49.75 \pm 3.090$ \\
CTCSF & $0.690 \pm 0.055$ & $1.11 \pm 0.041$ & $1.01 \pm 0.002$ & $32.35 \pm 0.999$ \\
CSF & $0.857 \pm 0.034$ & $1.21 \pm 0.040$ & $1.07 \pm 0.006$ & $44.09 \pm 1.296$ \\
AQSF & $0.786 \pm 0.028$ & $1.14 \pm 0.049$ & $1.19 \pm 0.003$ & $3.80 \pm 0.653$ \\
\hline Blank & $0.915 \pm 0.004$ & Water (blank) and Streptokinase (standard) & $66.77 \pm 0.662$ \\
\hline SK & $0.888 \pm 0.002$ & $1.12 \pm 0.002$ & $1.20 \pm 0.002$ & $1.10 \pm 0.010$ \\
\hline
\end{tabular}

$\mathrm{ME}=$ Methanolic extract; PESF $=$ Pet-ether soluble fraction of methanolic extract; $\mathrm{CTCSF}=$ Carbon tetrachloride soluble fraction of methanolic extract; $\mathrm{CSF}=$ Chloroform soluble fraction of methanolic extract; $\mathrm{AQSF}=$ Aqueous soluble fraction of methanolic extract; W1 $=$ Weight of micro centrifuge tube $(500 \mu \mathrm{l} /$ tube $)$ alone $(\mathrm{gm}) ; \mathrm{W} 2=$ Weight of clot containing tube $(\mathrm{gm}) ; \mathrm{W} 3=$ Weight of clot containing tube after clot disruption and removal of fluid; SK =Streptokinase

Table 2. Effect of different extractives of rhizome of $A$. indica on hypotonic solution-induced and heat iduced haemolysis of erythrocyte membrane

\begin{tabular}{lccc}
\hline Sample code & Concentration & \multicolumn{2}{c}{ \% Inhibition of haemolysis } \\
\cline { 3 - 4 } & & Heat induced & Hypotonic solution induced \\
\hline Hypotonic medium & $50 \mathrm{mM}$ & -- & -- \\
ME & $1 \mathrm{mg} / \mathrm{mL}$ & $35.37 \pm 1.43$ & $33.30 \pm 2.05$ \\
PESF & $1 \mathrm{mg} / \mathrm{mL}$ & $30.19 \pm 1.63$ & $52.66 \pm 2.06$ \\
CTCSF & $1 \mathrm{mg} / \mathrm{mL}$ & $17.36 \pm 1.60$ & $53.81 \pm 1.63$ \\
CSF & $1 \mathrm{mg} / \mathrm{mL}$ & $39.16 \pm 0.89$ & $22.54 \pm 1.32$ \\
AQSF & $1 \mathrm{mg} / \mathrm{mL}$ & $30.61 \pm 0.71$ & $44.77 \pm 0.80$ \\
Acetyl salicylic acid & $0.10 \mathrm{mg} / \mathrm{mL}$ & $42.20 \pm 1.65$ & $71.77 \pm 0.95$ \\
\hline
\end{tabular}


Table 3. Effect of different extractives of rhizome of $S$. virosa on hypotonic solution-induced and heat induced haemolysis of erythrocyte membrane

\begin{tabular}{cccc}
\hline Sample code & Concentration & \multicolumn{2}{c}{ \% Inhibition of haemolysis } \\
\cline { 2 - 4 } & & Heat induced & Hypotonic solution induced \\
\hline Hypotonic medium & $50 \mathrm{mM}$ & -- & -- \\
ME & $1 \mathrm{mg} / \mathrm{mL}$ & $32.39 \pm 2.74$ & $52.21 \pm 1.44$ \\
PESF & $1 \mathrm{mg} / \mathrm{mL}$ & $30.46 \pm 2.39$ & $43.58 \pm 1.11$ \\
CTCSF & $1 \mathrm{mg} / \mathrm{mL}$ & $20.55 \pm 1.98$ & $30.25 \pm 1.44$ \\
CSF & $1 \mathrm{mg} / \mathrm{mL}$ & $24.25 \pm 2.22$ & $40.61 \pm 2.04$ \\
AQSF & $1 \mathrm{mg} / \mathrm{mL}$ & $32.90 \pm 2.72$ & $54.74 \pm 1.09$ \\
Acetyl salicylic acid & $0.10 \mathrm{mg} / \mathrm{mL}$ & $42.20 \pm 1.65$ & $71.77 \pm 0.95$ \\
\hline
\end{tabular}

Table 4. Total phenolic content and cytotoxic activity of $A$. indica and $S$. virosa.

\begin{tabular}{cccc}
\hline Plant & Sample & $\begin{array}{c}\text { Total Phenolic Content }(\mathrm{mg} \text { of } \\
\text { GAE/ gm of dried extract }\end{array}$ & $\begin{array}{c}\text { Cytotoxic activity } \\
\left(\mathrm{LC}_{50} \mu \mathrm{g} / \mathrm{ml}\right)\end{array}$ \\
\hline \multirow{5}{*}{ A. indica } & VS & - & $0.45 \pm 0.45$ \\
& ME & $0.039 \pm 0.48$ & $5.39 \pm 0.67$ \\
& PESF & $0.067 \pm 1.07$ & $0.58 \pm 0.73$ \\
& CTCSF & $0.036 \pm 0.72$ & $0.50 \pm 0.84$ \\
& CSF & $0.027 \pm 0.93$ & $8.85 \pm 0.56$ \\
S. virosa & AQSF & $0.015 \pm 1.08$ & $77.64 \pm 0.45$ \\
& VS & - & $0.45 \pm 0.45$ \\
& ME & $0.015 \pm 1.25$ & $0.47 \pm 0.91$ \\
& PESF & $0.079 \pm 0.76$ & $0.49 \pm 0.79$ \\
& CTCSF & $0.014 \pm 0.87$ & $0.82 \pm 0.43$ \\
& CSF & $0.048 \pm 1.02$ & $1.03 \pm 0.85$ \\
& AQSF & $0.024 \pm 1.23$ & $2.40 \pm 0.59$ \\
\hline
\end{tabular}

$\mathrm{VS}=$ Vincristine sulphate; $\mathrm{ME}=$ Methanolic extract; PESF $=$ pet-ether soluble fraction; $\mathrm{CTCSF}=$ Carbon tetrachloride soluble fraction; $\mathrm{CSF}=$ chloroform soluble fraction; $\mathrm{AQSF}=$ Aqueous soluble fraction of the methanolic extract.

Table 5. Antimicrobial activity of $A$. indica extractives.

\begin{tabular}{lcccccc}
\hline & \multicolumn{7}{c}{ Diameter of zone of inhibition (mm) } & & \\
\cline { 2 - 6 } Test microorganisms & ME & PESF & CTCSF & CSF & AQSF & Ciprofloxacin \\
\hline Bacillus cereus & - & - & - & $9.67 \pm .57$ & - & $41.67 \pm 1.5$ \\
B. megaterium & - & - & - & - & - & $41.33 \pm 1.5$ \\
B. subtilis & - & $12.67 \pm 1.5$ & - & $12.0 \pm 1.0$ & - & $53.33 \pm .57$ \\
Staphylococcus aureus & $12.33 \pm 1.5$ & - & - & $14.0 \pm 1.0$ & - & $51.67 \pm .57$ \\
Sarcina lutea & - & - & - & $9.0 \pm 1.0$ & - & $47.67 \pm .57$ \\
Escherichia coli & - & - & - & $9.33 \pm 1.5$ & - & $51.0 \pm 1.0$ \\
Pseudomonas aeruginosa & $12.33 \pm .57$ & - & - & $14.33 \pm 1.5$ & - & $49.0 \pm 1.0$ \\
Salmonella typhi & - & - & - & - & - & $44.33 \pm 1.5$ \\
Sa. paratyphi & - & - & - & - & - & $54.67 \pm 1.5$ \\
Shigella boydii & $7.67 \pm .57$ & - & - & $12.33 \pm .57$ & - & $44.33 \pm 1.5$ \\
Sh. dysenteriae & - & - & - & $10.67 \pm 1.2$ & - & $51.0 \pm 1.0$ \\
Vibrio mimicus & - & - & - & $9.33 \pm 1.5$ & - & $49.67 \pm .57$ \\
V. parahemolyticus & $12.33 \pm .57$ & - & - & $14.33 \pm 1.5$ & - & $51.0 \pm 1.0$ \\
\hline
\end{tabular}

$\mathrm{ME}=$ Methanol extract; $\mathrm{PESF}=$ pet-ether soluble fraction; $\mathrm{CTCSF}=\mathrm{Carbon}$ tetrachloride soluble fraction; $\mathrm{CSF}=\mathrm{Chloroform}$ soluble fraction; $\mathrm{AQSF}=$ Aqueous soluble fraction of the methanolic extract of $A$. indica and S. virosa. 


\section{REFERENCES}

1. Mulla, W.A., Thorat, V.S., Patil, R.V., Burade, K.B. 2010. Anthelmintic activity of leaves of Alocasia indica (Linn.). Int. J. Pharm,Tech Res. 2, 26-30.

2. Kaisar, M.A., Rahman, M.S., Rahman, M.Z., Hasan, C.M. and Rashid, M.A. 2011. A review on phytochemicals from some medicinal plants of Bangladesh. J. Pharm. Nutr. Sci. 1, 87-95.

3. Sikder, M.A., Jisha, H.R., Kuddus, M.R., Rumi, F., Kaisar, M.A., and Rashid, M.A. 2012. Evaluation of Bioactivities of Nymphaea nouchali (Burm. f) - the National Flower of Bangladesh. Bang. Pharm. J. 15, 1-5.

4. Van Wagenen, B.C., Larsen, R., Cardellina, JH., Ran dazzo, D., Lidert, Z.C. and Swithenbank, C. 1993. Ulosantoin, a potent insecticide from the sponge Ulosa ruetzleri. J. Org. Chem. 58, 335-337.

5. Daginawala, H.F., Prasad, S., Kashyap, R.S., Deopujari, J.Y., Purohit, H.J. and Taori, G.M. 2006. Development of an in vitro model to study clot lysis activity of thrombolytic drugs. Thrombosis J. 4, 14.

6. Kawsar, M.H., Sikder, M.A., Rana, M.S., Nimmi, I. and Rashid, M.A. 2011. Studies of thrombolytic and cytotoxic properties of two asteraceous plants of Bangladesh. Bang. Pharm. J. 14, 103-106.
7. Shinde, U.A., Phadke A.S., Nair, A.M., Mungantiwar, A.A., Dikshit, V.J. and Saraf, M.N. 1999. Membrane stabilizing activity - a possible mechanism of action for the antiinflammatory activity of Cedrus deodara wood oil. Fitoterapia 70, 251-257.

8. Sikder, M.A., Rahman, M.A., Kaisar, M.A., Rahman, M.S., Hasan, C.M. and Rashid, M.A. 2011. In vitro Antioxidant, reducing power, free radical scavenging and membrane stabilizing activities of seeds of Syzygium cumini L. Lat. Am. J. Pharm. 30, 781-785.

9. Skerget, M., Kotnik, P., Hadolin, M., Hras, A., Simonic, M. and Knez, Z. 2005. Phenols, proanthocyanidins, flavones and flavonols in some plant materials and their antioxidant activities. Food Chem. 89, 191-198.

10. Meyer, B.N., Ferrigni, N.R., Putnam, J.E., Jacobsen, J.B., Nicholsand, D.E. and Mclaughlin, J.L. 1982. Brine shrimp, a convenient general bioassay for active plant constituents. Planta Med. 45, 31-34.

11. Maclaughlin, J.L., Anderson, J.E., Rogers, L.L. 1998. The use of biological assays to evaluate botanicals. Drug Info. J. 32, 513-524.

12. Ayafor, J.F. 1972. Limonoids and phytol derivatives from Cedrela sinensis. Tetrahedron 28, 9343.

13. Bayer, A.W., Kirby, W.M.M., Sherris, J.C. and Turck, M. 1966. Antibiotic susceptibility testing by a standardized single disc method. Am. J. Clin. Pathol. 45, 493-496. 